\section{O conselho municipal de saúde e o controle social em saúde: Curitiba como município de reflexão}

\section{Sutile, V M}

Cirurgiã-Dentista, Especialista em Saúde Coletiva e Mestranda em Bioética pela PUC/PR

Servidora Pública Municipal de Curitibal Brasil. e-mail: vsutile@gmail.com

\section{Rosaneli, C F}

Nutricionista, Doutora em Ciência da Saúde pela PUCPR e Pós-doutora em Bioética pelo Programa de Pós-graduação em Bioética da UnB. Professora da PUCPR/Brasil

Introdução: O Conselho Municipal de Curitiba foi constituído em 1991, conforme Lei Municipal no 7.631 de 17 de abril de 1991, seguindo a Lei 8.142/1990, desde então já realizou treze (13) Conferências Municipais de Saúde. O Conselho Municipal é composto por 36 membros titulares e 45 membros suplentes. As reuniões plenárias acontecem mensalmente. As pautas são organizadas com informes e temas debatidos e encaminhados em forma de propostas por onze (11) comissões temáticas, com representação paritária, que se reúnem uma vez ao mês. Além do Conselho Municipal, Curitiba conta com dez (10) Conselhos Distritais e cento de dez (110) Conselhos Locais de Saúde e, desde 2015 a renovação destes conselhos deve acontecer a cada quatro (4) anos. Metodologia: Relato de caso a partir da presença em reuniões ordinárias dos Conselhos e leitura de atas. Este relato, se dá sob a perspectiva como representante legal nos Conselhos Local, Distrital e Municipal e se debate com as relações estabelecidas entre usuários e demais segmentos do controle social do Conselho Municipal de Curitiba e não se propõe, neste estudo, aprofundar as demais relações estabelecidas dentro do Conselho Municipal de Saúde do Município analisado. Resultados: Observa-se que, muitos dos representantes de usuários que compõem os Conselhos Locais, Distritais e Municipal, são membros de associações de bairro, grupos de igrejas, associações de pais e mestres, grupos de usuários portadores de patologias e usuários que representam entidades de abrangência municipal. Em sua maioria, essas entidades e usuários têm pouca representatividade em suas comunidades e chegam aos Conselhos em busca de resolução de seus próprios problemas de saúde. O formato vigente de organização dos conselhos, desestimula, dificulta a participação e não propicia a renovação dentro dos Conselhos de Saúde, também favorece a manipulação de usuários que estão chegando nestes espaços pelos conselheiros mais antigos ou pelos trabalhadores, prestadores de serviço e gestores. A projeção de alguns conselheiros usuários, ocorre pela justa defesa de causas orgânicas de saúde. Todavia, muitos usuários advêm aos conselhos pela concordância com o posicionamento político do grupo hegemônico do município, repetindo um quadro já viciado na sociedade, isto é, utilizam-se da barganha e dominação para controlar do conselho. Então, o mote que conduziu inicialmente o usuário ao conselho de saúde, isto é, o debate sobre as causas de saúde nas comunidades, torna-se muitas vezes algo menor. Conclusão: A participação social é a forma legítima e democrática de efetivar a formulação e fiscalização das políticas de saúde no SUS, contudo exige diálogo, formação e novas pactuações entre os diferentes atores do controle social. O Controle Social em Curitiba, assim como em todo Brasil, foi responsável por muitas conquistas, porém pelo fato de ser um espaço vivo de tomada de decisão por parte dos usuários do sistema, ainda requer muitos avanços na qualificação de sua representatividade junto à sociedade para que seja reconhecido como ambiente político que promove saúde.

PALAVRAS-CHAVE: Controle Social e Conselhos de Saúde

\section{REFERÊNCIAS}

[1] CURITIBA. Secretaria Municipal da Saúde de. Conselho Municipal de Saúde.Curitiba.2018. Disponível em:

http://www.saude.curitiba.pr.gov.br/cms/sobre.html> Acesso em: 22 set.2018.

[2] CULIBABA, M.M, FALCÃO, L.K.C.E e ZOLET, R.T. As Conferências de Saúde: O Controle Social em Curitiba. In: Moysés, S.J.; Silveira-Filho A.D. (org). A Gestão Participativa na Saúde de Curitiba. Curitiba, Instituto Municipal de Administração Pública - IMAP ,2016 1 ed.172p.:XIII.

[3] LACAZ, F. A. de C.; FLORIO, S.M. R. Controle social, mundo do trabalho e as Conferências Nacionais de Saúde da virada do século XX. Ciênc. Saúde Coletiva, Rio de Janeiro, v. 14, n. 6, p. 2123-2134, Dec. 2009.

[4] 4)) BATAGELLO, R.; BENEVIDES, L.; PORTILLO, J.A.C. Conselhos de saúde: controle social e moralidade. Saúde soc. São Paulo, v. 20, n. 3, p. 625634.

[5] ROLIM, L. B.; CRUZ, R. de S. B. L. C.; SAMPAIO, K. J. A. de J. Participação popular e o controle social como diretriz do SUS: uma revisão narrativa. Saúde em Debate, Rio de Janeiro, v. 37, n. 96, p. 139-147, mar. 2013 